\title{
Stimuli-Responsive Polymer-Clay Nanocomposites under Electric Fields
}

\author{
Shang Hao Piao, Seung Hyuk Kwon and Hyoung Jin Choi * \\ Received: 15 October 2015; Accepted: 28 December 2015; Published: 15 January 2016 \\ Academic Editor: Biqiong Chen \\ Department of Polymer Science and Engineering, Inha University, Incheon 402-751, Korea; \\ sanghoo1105@inha.edu (S.H.P.); 22141016@inha.edu (S.H.K.) \\ * Correspondence: hjchoi@inha.ac.kr; Tel.: +82-32-860-7486; Fax: +82-32-865-5178
}

\begin{abstract}
This short Feature Article reviews electric stimuli-responsive polymer/clay nanocomposites with respect to their fabrication, physical characteristics and electrorheological (ER) behaviors under applied electric fields when dispersed in oil. Their structural characteristics, morphological features and thermal degradation behavior were examined by X-ray diffraction pattern, scanning electron microscopy and transmission electron microscopy, and thermogravimetric analysis, respectively. Particular focus is given to the electro-responsive ER characteristics of the polymer/clay nanocomposites in terms of the yield stress and viscoelastic properties along with their applications.
\end{abstract}

Keywords: polymer; clay; nanocomposite; electrorheological; conducting polymer

\section{Introduction}

Nanoscale materials have attracted considerable interest for their potential technological applications in a range of areas because their chemical and physical characteristics can be altered drastically from a macroscopic bulk to the molecular level. In particular, polymeric materials are being improved by forming polymer nanocomposite systems for desired engineering applications because of their synergistic effects on the molecular nanoscale from both pure polymers and inorganic materials [1-3]. Among the various inorganics for nanocomposites, there has been particular interest in polymer/clay nanocomposites consisting of a polymer and clay, in which the clay has been selected conventionally as fillers in polymer compound research and industrial applications [4,5]. Particles form internal interfaces with large specific surfaces in dispersions, making it possible to stabilize different director configurations, in which clay minerals are introduced to the structures, either intercalated or exfoliated, because of their small particle size, simple chemical modification mainly using cationic surfactants, layer expanding capabilities with various treatments, and low cost. On the other hand, it is well known that using molecular or nanoscale strengthening techniques instead of conventional particulate filled composites, polymer nanocomposites have the ability to extend their usage, through which they offer unique characteristics that are drastically different from their bulk counterparts [6-9]. Note that in conventional polymer/clay composites, the clay particles are simply dispersed as a filler in a polymer matrix, mainly to improve the mechanical and thermal properties, such as the heat-distortion temperature [10]. Nevertheless, the characteristics of a polymer-based nanocomposite immediately after its manufacture may be rather different from those of the same material after conversion to a final useful shape by some processing technique. In the case of polymer/clay nanocomposites, Wang et al. [11] reported that for a polypropylene/organic modified montmorillonite (MMT) nanocomposite processed via dynamic packing injection molding, the morphological change in the shear-induced morphology with a core in the center, an oriented zone surrounding the core and a skin layer in the cross-section areas of the samples was observed. Another processing technique of ultrasonication also affects the dispersion of clay in a polymer matrix [12]. 
Concurrently, polymer nanocomposites with conducting polymers with conjugated repeating units have facilitated the new development of enhanced thermal, electrical and optical properties $[13,14]$, via the appraisal of important parameters, such as electron affinities, ionization potential, band gap, and bandwidths [15-17], ensuring their potential engineering adoptability with better mechanical strength, dispersion stability or physical properties than pure conducting polymers [18-24]. In particular, the electrical conductivity can be controlled more easily, and the thermal or mechanical stability can be improved by the fabrication of the nanocomposites [25].

On the other hand, an electrorheological (ER) fluid is a type of smart and intelligent material that possesses extraordinary transition characteristics from a liquid-like to a solid-like state under an applied external electric field [26-30]. In general, a typical ER fluid is formed by electrically polarizable particles dispersed in a non-conducting medium, such as silicone oil or mineral oil [31-34]. The particles are dispersed randomly in the medium phase, exhibiting Newtonian fluid-like behavior when the external electric field is absent. On the other hand, when an electric field is applied to the fluid, all particles initially dispersed will become rapidly polarized and attract neighboring particles to form a chain-like structure with a robust dipole-dipole interaction aligned along the applied field. When the electric field strength is increased, the resulting chains agglomerate to produce stronger columns, indicating that the ER fluid is a more-like an elastic solid. During this electrically controllable and immediate process, the rheological property of the ER fluids can generally be expressed using a Bingham fluid model. Compared to the liquid-like state of ER fluids without an electric field, the solid-like state induced by an external electric field is provided with a non-vanishing yield stress, higher shear viscosity and dynamic moduli. Therefore, similar to the case of the magnetorheological (MR) fluids under a magnetic field [35-37], the ER fluids have a considerable potential in a variety of engineering applications, such as dampers, torque transducers, optical finishing, and haptic devices [38-40].

Various electro-responsive materials, including biopolymers, such as cellulose and starch, inorganic particles, such as titania, zeolite, mesoporous material, and silica, and conducting polymers demonstrate typical ER behaviors, while hybrids of organic/inorganic materials have been introduced because of their enhanced characteristics [25].

This paper reviews the fabrication methods and characteristics of smart polymer/clay nanocomposites used as ER materials prepared from a range of different fabrication methods. The ER performance of the polymer/clay nanocomposites was observed by either optical microscopy or rotational rheometry.

\subsection{Fabrication of Electro-Responsive Polymer/Clay Nanocomposites}

As a simple and interesting way to construct organic-inorganic hybrid systems and provide synergistic properties, which cannot be achieved from individual materials, such as easily controlled conductivity and higher mechanical stability, several methods to prepare electro-responsive polymer/clay nanocomposites have been reported $[25,40]$.

\subsubsection{In-Situ Chemical Oxidation Polymerization}

Yeh et al. [41] introduced a polyaniline (PANI)/clay nanocomposite by effectively dispersing the inorganic nanolayers of montmorillonite (MMT) clay in an organic PANI matrix via in-situ polymerization. Initially, an appropriate amount of organophilic clay was added to an aqueous $\mathrm{HCl}$ solution, and the organic aniline monomers were added to the solution for intercalation into the interlayer regions of the organophilic clay hosts. Upon the addition of ammonium persulfate (APS) in $\mathrm{HCl}, \mathrm{HCl}$-doped lamellar nanocomposite precipitates were obtained. The final nanocomposite products were obtained by immersing the $\mathrm{HCl}$-doped nanocomposites into aqueous an $\mathrm{NH}_{4} \mathrm{OH}$ solution, followed by filtration and drying. PANI/clay nanocomposites were prepared in the form of coatings with a low clay loading from 0.75 to $3 \mathrm{wt} \%$. Scheme 1 presents a diagram of the experimental procedure. 


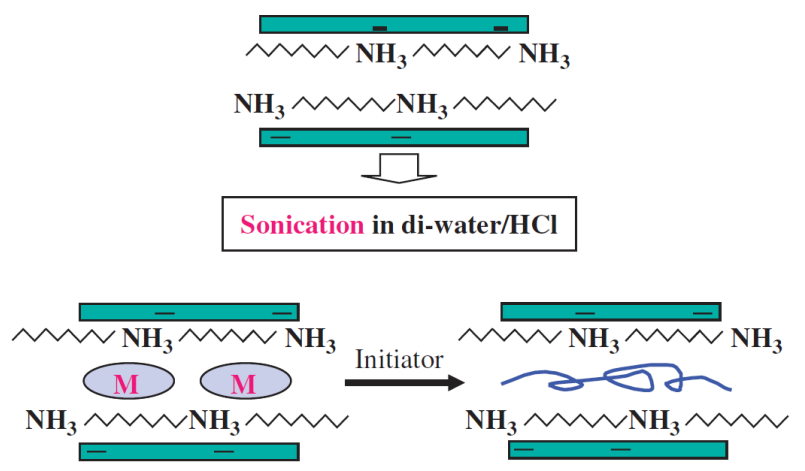

Scheme 1. Preparation of the polyaniline (PANI)/clay nanocomposite via an in-situ polymerization (Reprinted from Reference [25] with permission).

Furthermore, using a copolyaniline of poly(o-ethoxyaniline) (PEA), Yeh et al. fabricated PEA/MMT nanocomposites with different clay loadings up to $5 \mathrm{wt} \%$, finding that the nanocomposites at low clay loadings up to $3 \mathrm{wt} \%$ exhibited a much superior corrosion inhibition effect compared to pristine PEA [42].

Concurrently, using other types of tube-like clay particles, the PANI/halloysite (HNT) nanocomposites have been also reported [43-45]. Zhang et al. [45] reported the facile synthesis of organic/inorganic PANI-wrapped HNT composite by the in situ polymerization of aniline in a HNT dispersion using APS as an initiator, and adopted it as an ER potential material.

Chea et al. [46] fabricated palygorskite (Pal) clay coated with semiconducting PANI nanocomposite particles by an oxidative polymerization process, as shown in Scheme 2 and used them as ER materials without a post-treatment step except for the doping process. Sulfuric acid was added drop-wise to initiate aniline polymerization. The sulfuric acid-modified aniline monomer was then polymerized with the aid of APS at the surface of Pal, resulting in Pal/PANI composite particles.

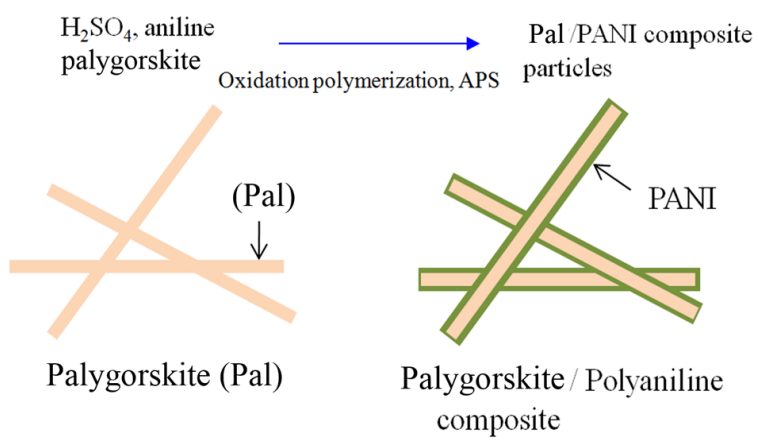

Scheme 2. Schematic diagram of the experimental route to synthesize the palygorskite (Pal)/PANI composite particles.

\subsubsection{Suspension Polymerization}

Compared to other polymerization processes in electro-responsive polymer/clay nanocomposites, suspension polymerization was seldom adopted. Jun and Suh [47] synthesized poly(urethane acrylate) (PUA)/clay nanocomposite particles by suspension polymerization, with a continuous phase comprised of an aqueous solution of poly(vinyl alcohol) and sodium nitrite, and the dispersed phase comprised of monomer, toluene as an organic diluent, and the oil-soluble initiator with a clay content of $5 \mathrm{wt} \%$. They then examined their ER characteristics.

\subsubsection{Emulsion Polymerization}

The emulsion polymerization process is considered to be a very useful fabrication technique for synthesizing polymer/clay nanocomposites using glassy polymers with high glass-transition 
temperatures, such as poly(methyl methacrylate) (PMMA), polystyrene (PS) and styrene-acrylonitrile (SAN), and epoxy and rubbery polymers, such as poly(ethyl acrylate) $[25,48]$. Kim et al. [49] synthesized SAN copolymer- $\mathrm{Na}^{+}-\mathrm{MMT}$ clay nanocomposite particles by emulsion polymerization and examined their ER performance. For the emulsion polymerization of polymer nanocomposites, the $\mathrm{Na}^{+}-\mathrm{MMT}$ clay was introduced to synthesize a polymer/clay nanocomposite with SAN in the presence of potassium persulfate as an initiator and sodium lauryl sulfate as an emulsifier, and the product was then coagulated by the addition of aluminum sulfate solution. The final weight fraction of the $\mathrm{Na}^{+}$-MMT in the SAN/clay nanocomposite was $4.76 \mathrm{wt} \%$. ER fluids composed of SAN-clay composite exhibited typical ER behavior and possessed "pseudo-Newtonian" behavior at high shear rates.

\subsubsection{Pickering Emulsion Polymerization}

Recently, the Pickering emulsion polymerization process has attracted considerable attention as a new method for the fabrication of smart nanocomposites, in which the emulsion droplets prior to polymerization are being stabilized by various solid particles instead of conventional organic surfactants or stabilizers. Therefore, Pickering emulsions impart better stability against coalescence and, in many cases, are biologically compatible and environmentally friendly [50]. Although Pickering emulsions have huge industrial potential applications in the areas of petroleum, food, biomedicine, pharmaceuticals, and cosmetics, Pickering emulsion polymerized particles have recently been adopted for both ER and MR materials [51].

Fang et al. [52] fabricated PANI/clay nanoparticles with a special core-shell structure via Pickering emulsion in a toluene phase by employing an exfoliated clay sheet as a stabilizer, using organophilically modified MMT (OMMT). The synthesized PANI nanospheres, which were initialized by oil-soluble benzoyl peroxide, possessed a polydisperse size distribution of particles, ranging from $200 \mathrm{~nm}$ to $1 \mu \mathrm{m}$.

Kim et al. [53] introduced polystyrene (PS)/laponite composite nanoparticles fabricated using Pickering emulsion polymerization. The hydrophilic laponite modified with cetyltrimethylammonium bromide was used as a stabilizer, in which emulsions of styrene were dispersed in water. Scheme 3 outlines the mechanism for preparing PS/laponite core-shell particles by surfactant-free Pickering emulsion polymerization. The modified laponite was adsorbed on the surface of the styrene monomer droplet to stabilize the system. After adding a water soluble initiator, the mixture became milky white and polymerization occurred in the styrene droplets with laponite adsorbed at the boundary surface. The weight ratio of laponite in the PS/laponite nanoparticles was approximately $8.85 \%$.

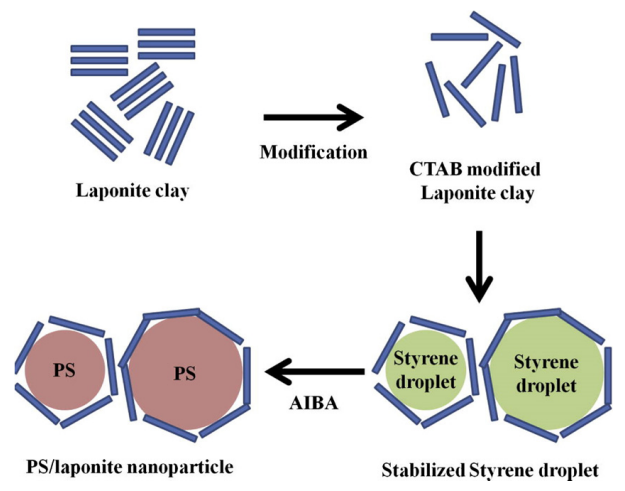

Scheme 3. Mechanism of surfactant-free Pickering emulsion polymerization for polystyrene (PS)/laponite nanoparticles (Reprinted from Reference [53] with permission).

\subsection{Melt Processing}

Based on the effects of the applied electric field on the structural evolution of poly(propylene) (PP)/clay nanocomposites, showing a tendency toward exfoliation [54], Kim et al. [55] reported a novel method to produce poly(propylene)/clay nanocomposites continuously with a clay content of $5 \mathrm{wt} \%$ 
using an electric melt pipe equipped with a twin-screw extruder, as shown in Scheme 4 . In their study, partial intercalation was obtained by continuous processing, showing the possibility to produce nanocomposites using this method. As this physical process can be appropriate for conventional extrusion, the approach may also be used in other polymer/clay nanocomposite systems [55].

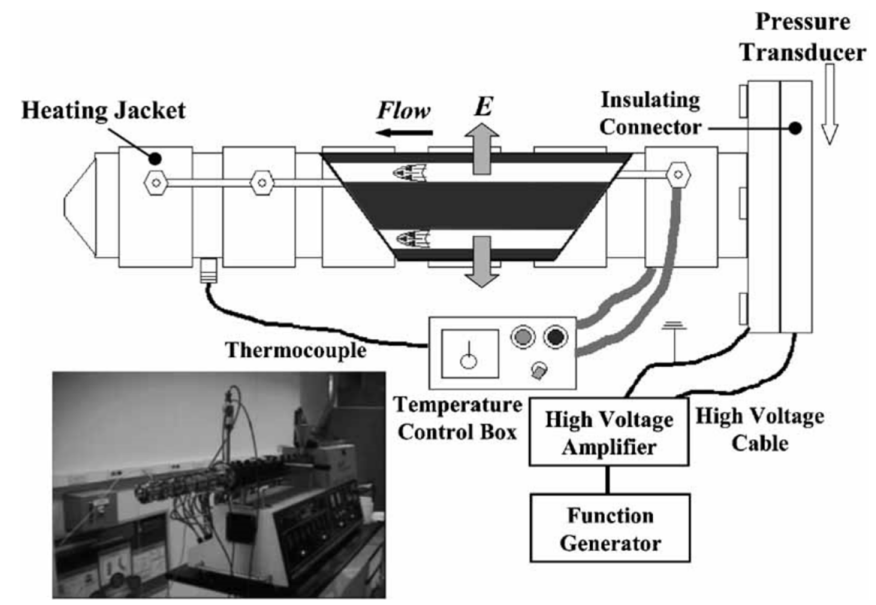

Scheme 4. Schematic diagram of an electric melt pipe equipped with a twin-screw extruder. (Reprinted from Reference [55] with permission).

\section{Characterization of Polymer-Clay Nanocomposites}

\subsection{Morphology}

Once the electro-responsive smart polymer/clay nanocomposites were synthesized, their morphology was examined to determine if the nanocomposite had been synthesized successfully. These can be answered by either scanning electron microscopy (SEM) or transmission electron microscopy (TEM).

Figure 1 provides direct evidence of the synthesis of a PANI-coated HNT surface provided by the SEM images, in which the neat nanotubes of the raw HNT can be seen. Compared to the pure HNT, the distinctive tubular shape of the PANI/HNT composite in Figure 1b disappeared, indicating the formation of PANI.

Regarding the morphology of the PANI/OMMT nanocomposite confirmed by SEM (Figure 2a), pure clay exhibits a lamellar structure with a nanosized thickness and huge surface area in each layer. After the polymerization of aniline, a large number of nano-granules were observed with a broad particle size distribution, as shown in Figure $2 b$. The granular surface became rough due to the adsorbed OMMT sheets [56-59]. Therefore, the PANI/OMMT nanocomposite particles have a core-shell structure, in which the core material is an organic PANI and the shell material is the exfoliated clay sheet.
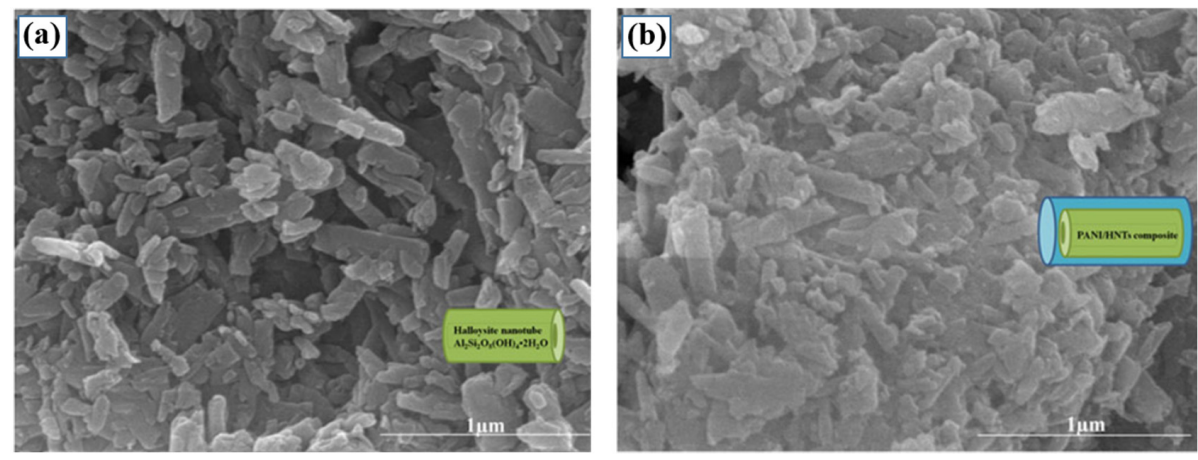

Figure 1. Scanning electron microscopy (SEM) images of (a) halloysites (HNTs) and (b) PANI/HNT composites (Reprinted from Reference [45] with permission). 

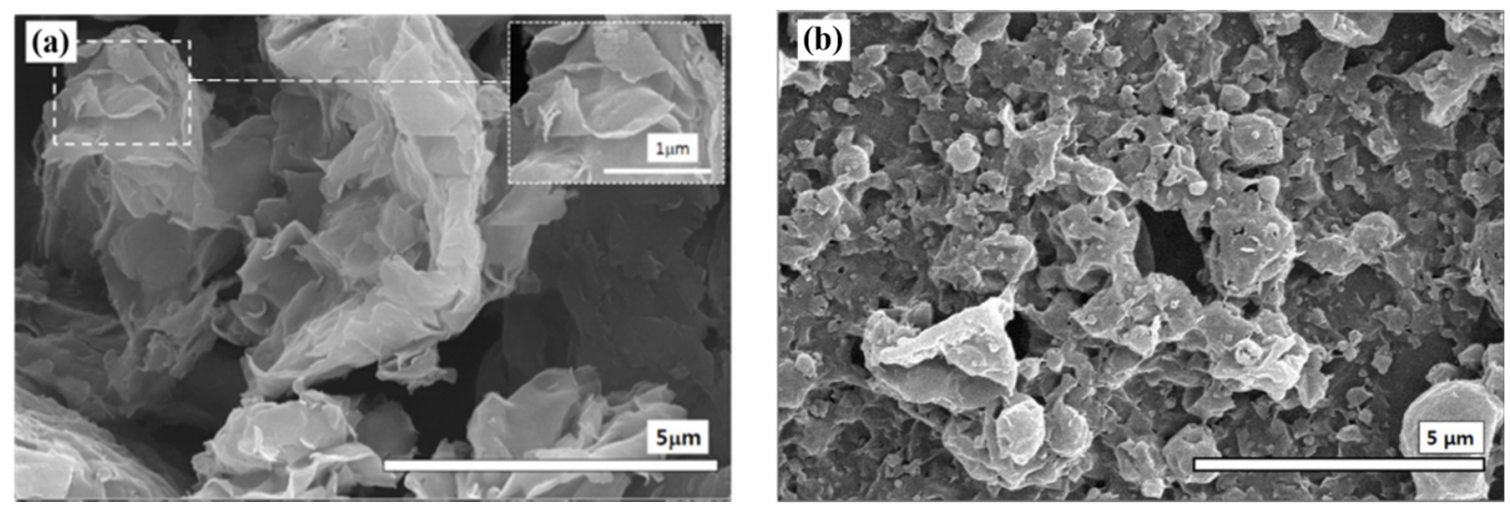

Figure 2. SEM images of pristine clay (a) and fabricated PANI/OMMT nanocomposite particles (b) (Reprinted from Reference [52] with permission).

The morphologies of both Pal/PANI and Pal were examined by TEM to characterize the surface morphology of the pure Pal (Figure 3a) and Pal/PANI particles (Figure 3b). Figure 3a showed that the surface of Pal was quite smooth, in which Pal has a highly fibrous morphology that forms bundles. The length of each fiber was varied from the sub-micrometer to micrometer range with a mean diameter of approximately $20 \mathrm{~nm}$. In contrast, the Pal/PANI composite particles had a much rougher surface due to the wrapping of PANI (Figure 3b), meaning that the aniline had been polymerized onto the Pal template by a chemical oxidation method, altering the outside surface.
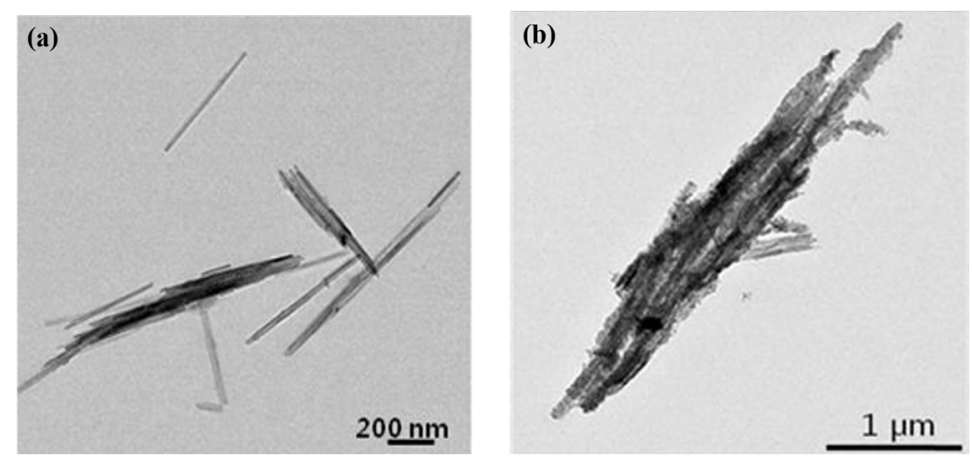

Figure 3. Transmission electron microscopy (TEM) images of Pal (a) and Pal/PANI composite particles (b), respectively (Reprinted from Reference [46] with permission).

Fang et al. [60] published a TEM image of a cross-sectional view of the synthesized nano-sized laponite stabilized poly(methyl methacrylate) (PMMA) spheres, as shown in Figure 4. The PMMA nanospheres were synthesized by surfactant-free Pickering emulsion polymerization, the emulsions of methyl methacrylate (MMA) monomer were dispersed in water stabilized by the hydrophilic laponite clay. The grey spherical regions were considered to be PMMA cores and the dark strips were laponite plates. The grey cores were surrounded by multitudinous densely stacked laponite plates, demonstrating the role of laponite plates as a stabilizer. 


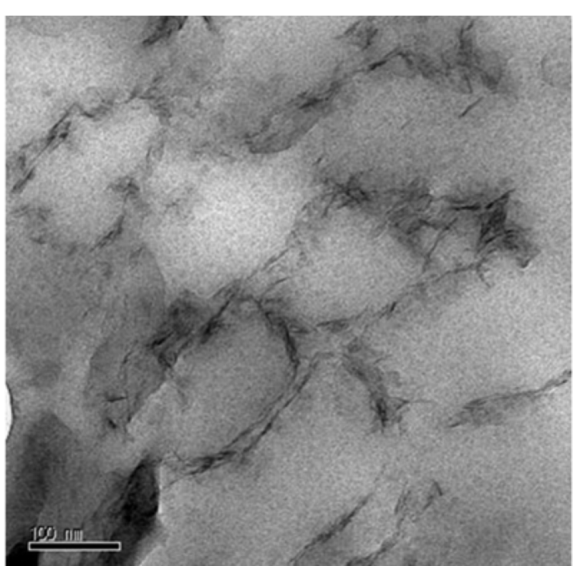

Figure 4. TEM image of a poly(methyl methacrylate) (PMMA) nanoparticle stabilized by laponite (Reprinted from Reference [60] with permission).

\subsection{Crystalline State}

In the case of crystalline clay, the delicate layer-layer structure and the changes in the d-spacing between adjacent layers were examined by X-ray diffraction (XRD). The initial XRD patterns were different from the final XRD patterns, in which the characteristic peak for clay showed a shift in intensity and position.

From the XRD pattern of pure clay and PANI/clay nanoparticles [61] (Figure 5), the salient peak (d001) equivalent to the basal spacing of MMT was calculated to be $3.25 \mathrm{~nm}$ using the Bragg Equation: $\lambda=2 d \cdot \sin \theta(\lambda=0.154 \mathrm{~nm})$ [62]. The PANI/clay nanoparticles in Figure 5 showed no distinct sharp peak but a wide plateau, proving the disappearance of the layered structure. Nevertheless, it can be deduced that a few clay particles were not exfoliated, and the entire exfoliation of clay remains a difficult task [63].

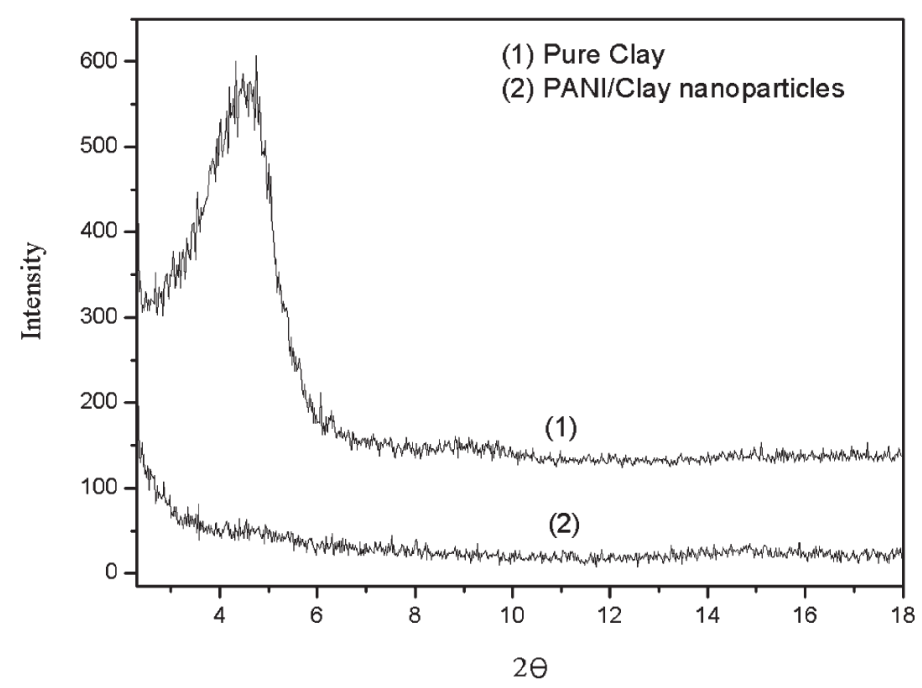

Figure 5. X-ray diffraction (XRD) patterns of pure clay (1) and clay sheet-stabilized polyaniline granules (2) (Reprinted from Reference [61] with permission).

Figure 6 presents XRD patterns of Pal, PANI and synthesized Pal/PANI nanocomposite particles. The crystalline PANI possessed reflections at $18.4^{\circ}$ and $25.7^{\circ} 2 \theta$. The reflection centered at $18.4^{\circ} 2 \theta$ was due to the periodicity in the orientation parallel to the polymer chain, while the peak at $25.7^{\circ} 2 \theta$ was assigned to the periodicity in the orientation perpendicular to the polymer chain [64]. For Pal, the representative reflections were observed at $8.3^{\circ}, 13.6^{\circ}, 19.7^{\circ}$ and $26.6^{\circ} 2 \theta$, which were assigned to 
the (1 1 0), (2 0 0), (0 4 0) and (4 0 0) planes of Pal, respectively [65]. Pal/PANI showed a similar set of characteristic reflections, which means that the crystal structure of Pal has been maintained during its polymerization reaction. The PANI reflection in Pal/PANI is almost invisible because Pal/PANI has a relative thin layer of amorphous PANI synthesized by this polymerization reaction [65].

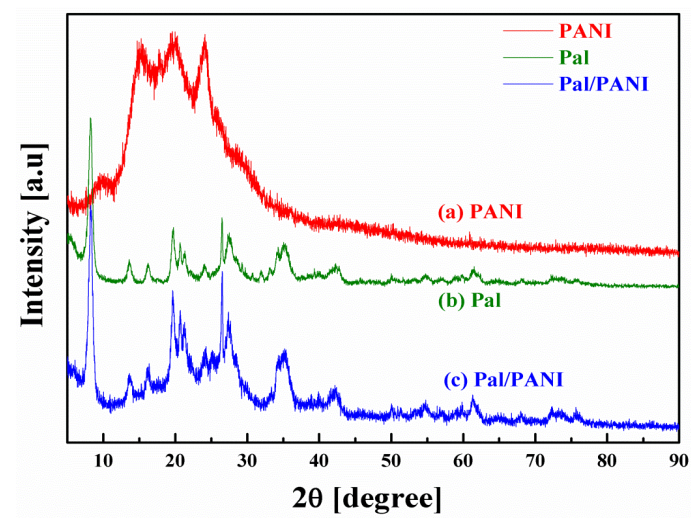

Figure 6. XRD patterns for pristine PANI (a), Pal (b) and Pal/PANI (c) (Reprinted from Reference [46] with permission).

\subsection{Thermal Properties}

The nanoscopic combination of conducting polymers with clay affects the thermal performance, in which the enhanced thermal properties are due to the significant enhancements in the interfacial conglutination between the polymer and clay [66]. Generally, better interfacial bonding imparts better properties to a polymer nanocomposite, such as tensile strength, hardness and high modulus, as well as resistance to fatigue, tear, corrosion and cracking [67]. Thermogravimetric analysis (TGA) shows the changed thermal behaviors.

Figure 7 presents the weight composition and thermal stability of the HNT and polypyrrole (PPy)/HNT nanocomposite [68]. The PPy/HNT nanocomposites exhibited two-step thermal degradation behavior with the first weight loss from $300{ }^{\circ} \mathrm{C}$ and the second thermal degradation from $500{ }^{\circ} \mathrm{C}$, indicating that they were thermally stable up to $300^{\circ} \mathrm{C}$. A sharp loss in mass was observed at 300 and $500{ }^{\circ} \mathrm{C}$, possibly due to the large scale thermal degradation of the PPy chains [69] and the dehydroxylation of HNT [70]. On the other hand, this char formation temperature indicates the increased thermal stability of the polymer/clay nanocomposite [71].

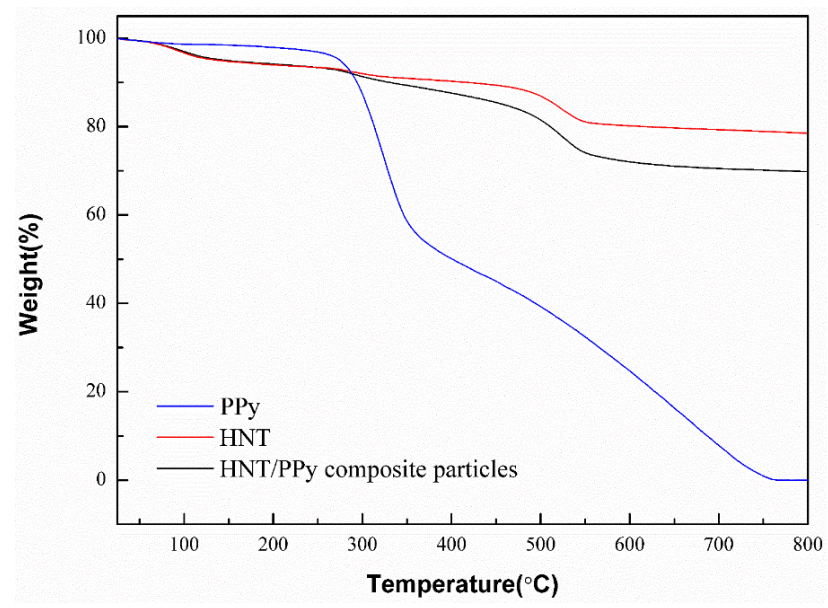

Figure 7. Thermogravimetric analysis (TGA) curve of HNT and PPy/HNT composite (Reprinted from Reference [68] with permission). 


\section{Electrorheological (ER) Characteristics}

Kim et al. [53] prepared the an ER fluid by dispersing the PS/laponite nanoparticles in silicone oil and observed its structural change directly by optical microscope (OM) under an external electric field with a Direct current (DC) high voltage source. The PS/laponite nanoparticle-based ER fluid exhibited a typical ER chain structure. In the absence of an electric field, the particles were dispersed randomly in silicone oil, indicating a liquid-like state (Figure 8a). In an applied electric field, the particles moved immediately and formed a chain structure aligned along the orientation of the applied electric field (Figure 8b). Normally, this phenomenon of chain formation under an external applied electric field can be maintained as long as the electric field is applied.
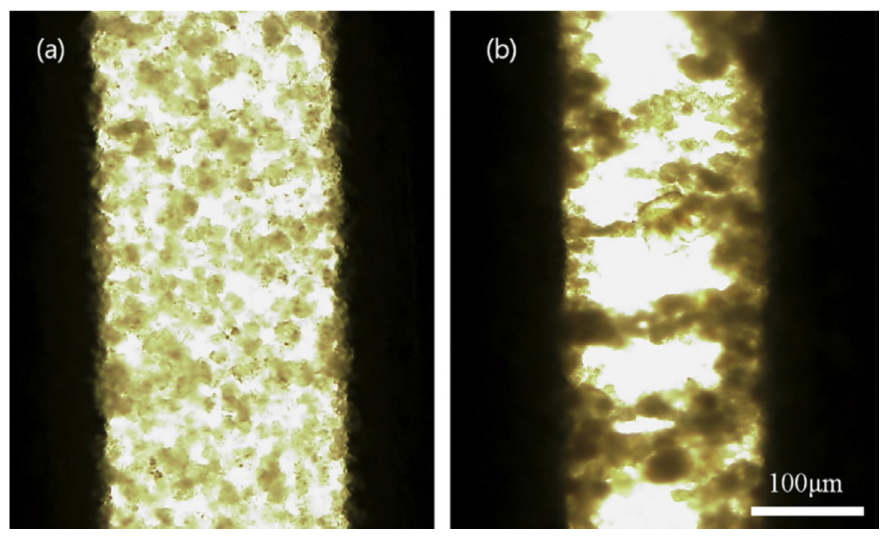

Figure 8. Optical microscope (OM) images of the electrorheological (ER) fluid based on PS/laponite nanoparticles in the absence of an electric field (a) and in an electric field (b) (Reprinted from Reference [53] with permission).

Owing to the dielectric polarization [72,73] of ER fluids arising from the mismatch between the dielectric constants of the medium oil and the dispersed nanocomposites, particulate materials with a higher dielectric constant [74], are expected to be beneficial for the superior ER effects. Figure 9 shows the variation of the dielectric constants as a function of the applied electrical frequency for the PUA and PUA/clay composite particles [47]. The clay amalgamated PUA particles showed significantly improved dielectric constant values than the bare PUA particles.

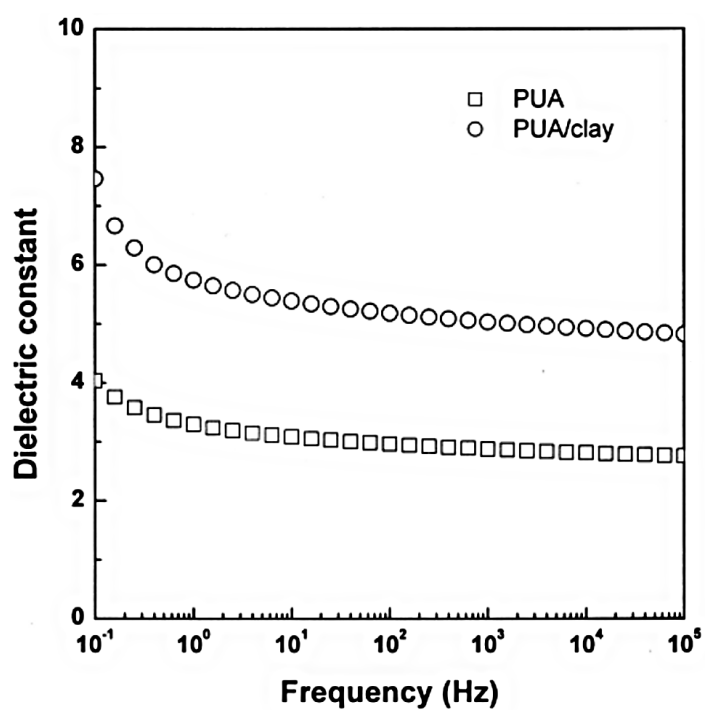

Figure 9. Dielectric constants as a function of the applied electrical frequency for bare poly(urethane acrylate) (PUA) and PUA/clay composite particles (Reprinted from Reference [47] with permission). 
Regarding the flow curve, however, the Pal/PANI nanocomposite particle-based ER fluid exhibited an unusual decreasing trend in shear stress at a low shear rate region, and an increased shear stress with an increasing shear rate. The chain structures began to deteriorate with hydrodynamic shear deformation, and the damaged structures tended to reform the chains repeatedly due to the applied electric field, depending on the magnitude of the applied shear and the particle to particle interactions in the fibrils. In the low shear rate region, the electrostatic interactions were dominant [75,76]. At a high shear rate region, where the hydrodynamic interaction was greater, the broken chain particles had less chance to reform and the ER fluid behaved like a pseudo-Newtonian fluid [75]. Therefore, the Bingham fluid model and Cho-Choi-Jhon (CCJ) model were used to explain the shear stress behavior and yield stress [76].

The Bingham fluid model shown in Equation (1), which is the simplest model with two parameters originating from Newtonian viscosity $\left(\eta_{0}\right)$ and yield stress $\left(\tau_{0}\right)$, is used widely to describe the shear stress behavior of ER suspensions and conventional suspension systems.

$$
\begin{gathered}
\tau=\tau_{0}+\eta_{0} \dot{\gamma}\left(\tau \geqslant \tau_{0}\right) \\
\dot{\gamma}=0\left(\tau<\tau_{0}\right)
\end{gathered}
$$

where $\tau$ represents the shear stress and $\dot{\gamma}$ is the shear rate. The dotted lines in Figure 10a were from Equation (1). The simple Bingham model, however, could not be fitted to the flow curve of Pal/PANI ER fluid. Therefore, the CCJ model shown in Equation (2) was suggested to re-plot the shear stress behavior by fitting the curves using six parameters [75].

$$
\tau=\frac{\tau_{0}}{1+\left(t_{1} \dot{\gamma}\right)^{\alpha}}+\eta_{\infty}\left(1+\frac{1}{\left(t_{2} \dot{\gamma}\right)^{\beta}}\right) \dot{\gamma}
$$

where $\eta_{\infty}$ represents the viscosity at the infinite shear rate that is interpreted as the viscosity in the absence of an external electric field. The parameters, $t_{1}$ and $t_{2}$, are time constants, the exponents $\alpha$ and $\beta$ are defined as the decrease and increase in shear stress; the exponents $\beta$ has the range $0<\beta \leqslant 1$, due to $\frac{\mathrm{d} \tau}{\dot{\gamma}} \geqslant 0$ [68]. Figure 10a shows the fitting of the two model equations for the Pal/PANI composite-based ER fluid. The solid lines from the CCJ model showed a better fit to the flow curves than the dotted lines generated by fitting the Bingham model in both the low and high shear rate regions [75].

As shown in Figure 10b, the shear viscosity exhibited shear thinning behavior as a function of the shear rate as similar to that in various polymeric systems [77]. Generally, the non-Newtonian behavior in the absence of an electric field is due to the particle dispersed state in a high concentrated ER fluid.
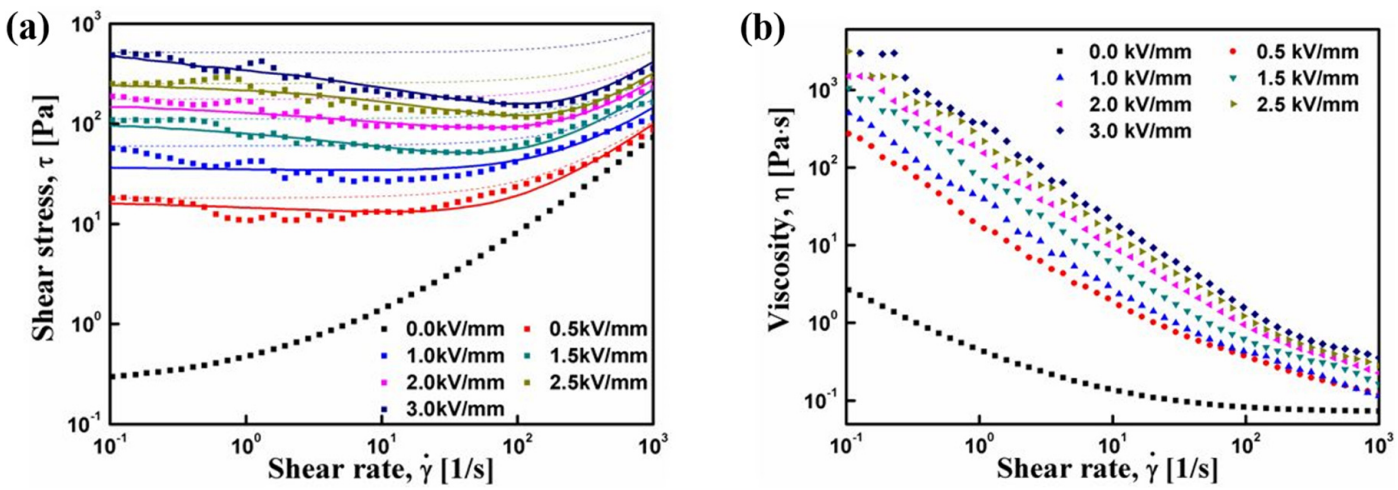

Figure 10. Shear stress (a) and shear viscosity (b) curves vs. shear rate for Pal/PANI based on ER fluids (10 vol. \%) under a range of electric field strengths, the dashed lines were fitted using a conventional Bingham model, the solid lines were fitted via a suggested CCJ model (Reprinted from Reference [46] with permission). 
The dynamic yield stress is a characteristic factor of an ER fluid. In Figure 11, the dynamic yield stress of the Pal/PANI composite particle-based ER fluid was plotted as a function of the electric field strength $(E)$ in log-log scale curves. The yield stress $\left(\tau_{y}\right)$ of an ER fluid is related to the electric field strength, and can be described as a power law relationship:

$$
\tau_{y} \propto E^{\mathrm{m}}
$$

where the exponent $m$ was obtained by fitting the yield stress over a broad electric field range. The dependence of the dynamic yield stress could be expressed as $\tau_{y} \propto E^{2}$, which is a polarization model of the ER mechanism [78].

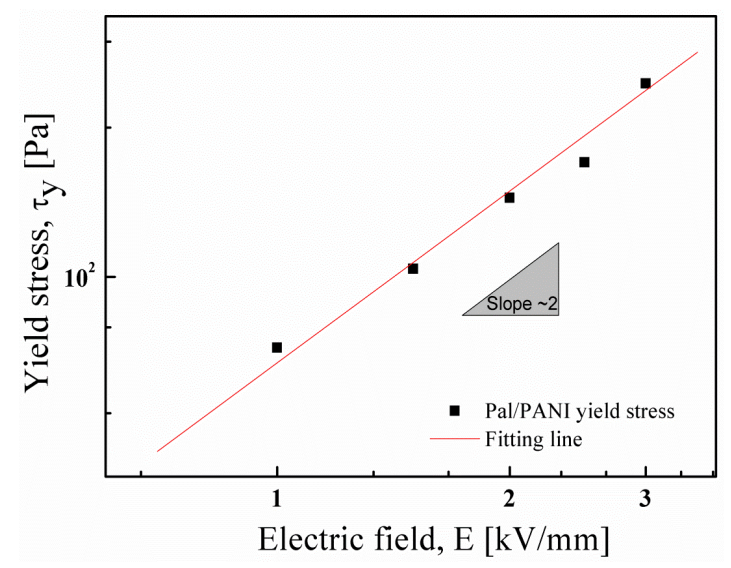

Figure 11. Dynamic yield stress as a function of the electric field strength of the Pal/PANI composite particles based ER fluid. The solid line was fitted using the equation, $\tau_{y} \propto E^{2}$ (Reprinted from Reference [46] with permission).

Volume fraction of electro-responsive ER particles dispersed in the suspension is one of the major factors that affect the electric field dependent shear viscosity [79-83]. Guzel et al. [81] fabricated polyindene (PIN) and three volume fractions of OMMT nanocomposites namely K1 (5.5\%), K2 $(7.2 \%)$ and K3 (12.1\%) to study their ER characteristics. Figure 12 shows the change of the electric field-dependent shear viscosity with clay volume fraction at constant conditions $(E=3 \mathrm{kV} / \mathrm{mm}$, $\dot{\gamma}=1 \cdot \mathrm{s}^{-1}, T=25^{\circ} \mathrm{C}$ ). The higher particle concentration leads to the intensive particle chains formed by the influence of an external electric field, resulting in a higher resistance to flow.

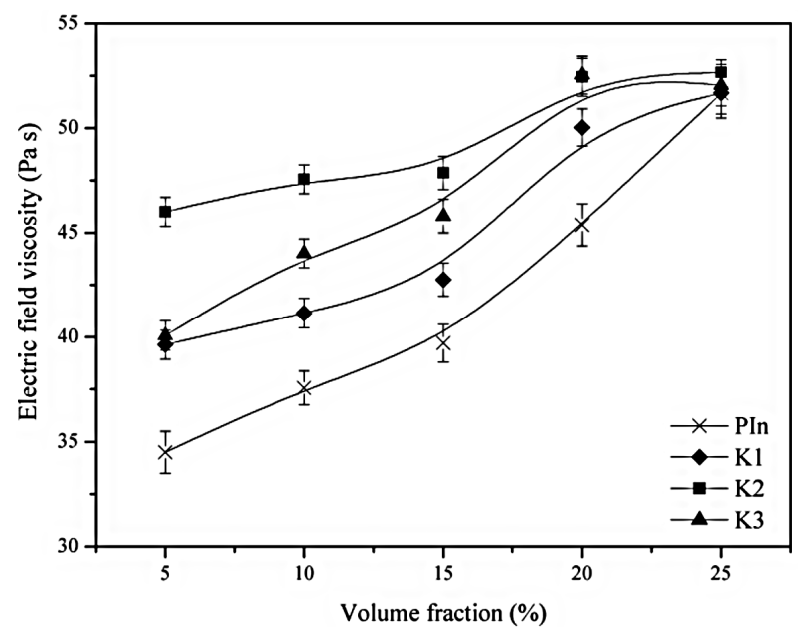

Figure 12. Effect of volume fraction on electric field viscosity $\left(E=3 \mathrm{kV} / \mathrm{mm}, \dot{\gamma}=1 \cdot \mathrm{s}^{-1}, \mathrm{~T}=25^{\circ} \mathrm{C}\right)$. (Reprinted from Reference [81] with permission). 
Furthermore, Eristi et al. [80] synthesized PIN and five PIN/kaolinite composites containing different amounts of kaolinite of K1 (78\%), K2 (63\%), K3 (47\%), K4 (25\%) and K5 (15\%). Figure 13 shows that the electric field-dependent shear viscosity increased with enhanced electric field strength. However at a given electric field applied of $3 \mathrm{kV} / \mathrm{mm}$, it was observed that the electric field viscosity reduced with increasing clay content.

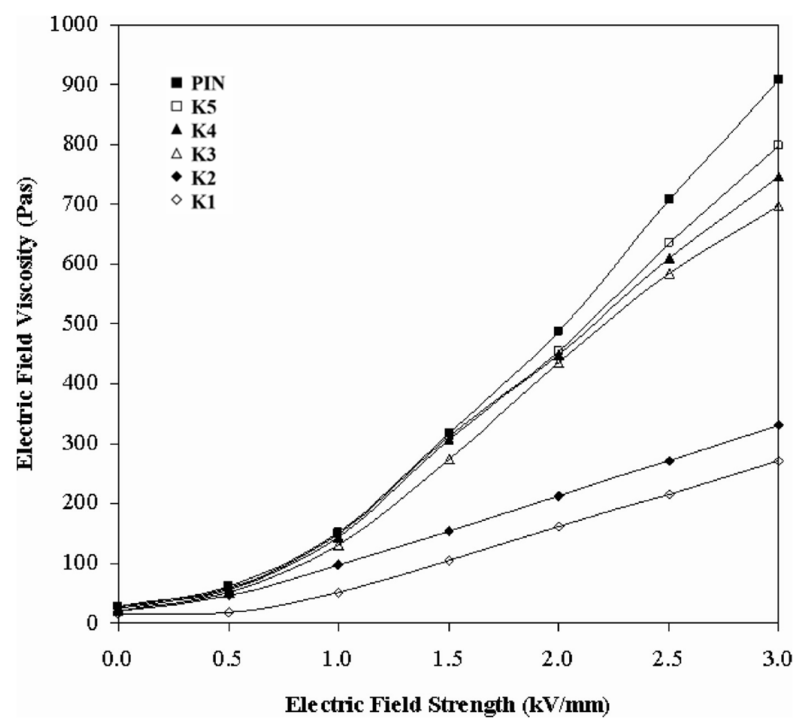

Figure 13. The change of viscosity with electric field strength, $\left(c=15(\mathrm{~m} / \mathrm{m}, \%), \dot{\gamma}=1.0 \cdot \mathrm{s}^{-1}, \mathrm{~T}=25^{\circ} \mathrm{C}\right)$. (Reprinted from Reference [80] with permission).

Figure 14 compares the frequency dependence of the storage modulus $\left(G^{\prime}\right)$ and loss modulus $\left(G^{\prime \prime}\right)$ of a PPy/HNT fluid, the measured frequency range was 1-100 rad/s. In the absence of an electric field, the storage modulus increased linearly with frequency, showing liquid-like characteristics. In an applied external electric field, the $G^{\prime}$ and $G^{\prime \prime}$ values increased in proportion to the electric field. The $G^{\prime}$ values representing an elastic response were higher than those of $G^{\prime \prime}$, representing viscous property indicating that the ER fluid has very strong solid-like behavior, which is the dominant factor of the elastic property over the viscous one.
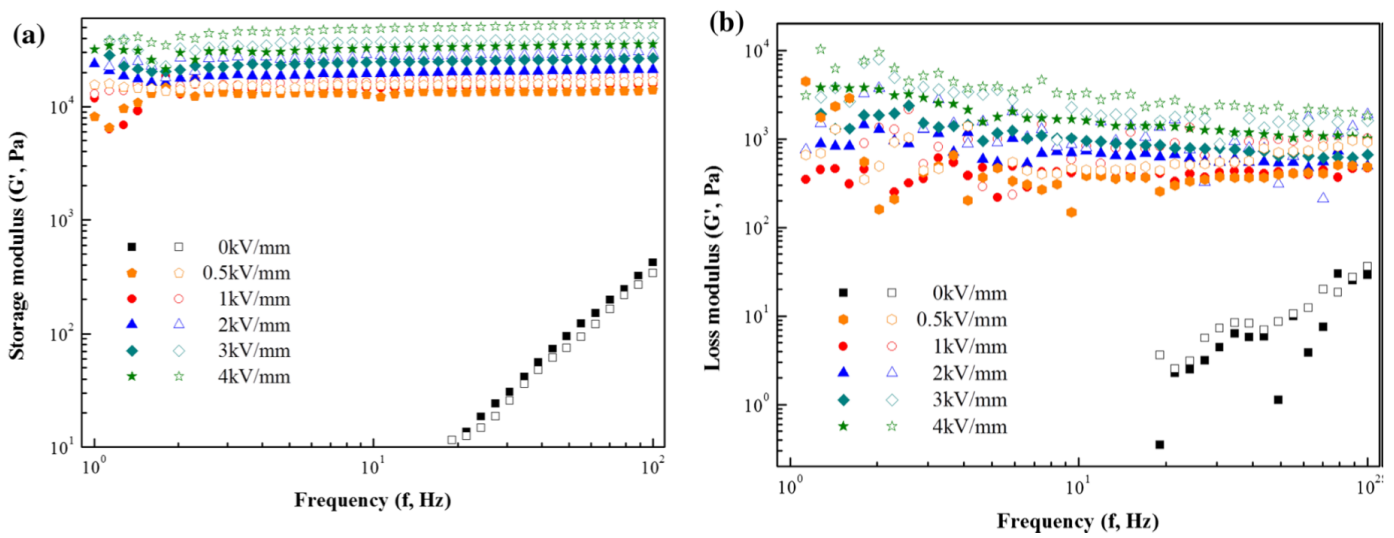

Figure 14. Storage modulus (a) and loss modulus (b) versus frequency for PPy/HNT composite-based ER fluid (close symbol $10 \mathrm{vol}$. \% and open symbol 15 vol. \% particle concentration) under various electric field strengths (Reprinted from Reference [68] with permission).

To further examine the ER characteristics of the PS/laponite nanoparticle-based ER fluid, the relationship between dielectric and ER properties were examined using an inductance capacitance 
resistance (LCR) meter. Figure 15 shows the dielectric spectra and Cole-Cole plot, respectively [84]. Both the permittivity $\left(\varepsilon^{\prime}\right)$ and loss factor $\left(\varepsilon^{\prime \prime}\right)$ were measured as a function of frequency $(\omega)$. The model is represented in terms of the complex dielectric constant as follows:

$$
\varepsilon^{*}=\varepsilon^{\prime}-\varepsilon^{\prime \prime}=\varepsilon_{\infty}+\frac{\Delta \varepsilon}{(1+i \omega \lambda)^{1-\alpha}}
$$
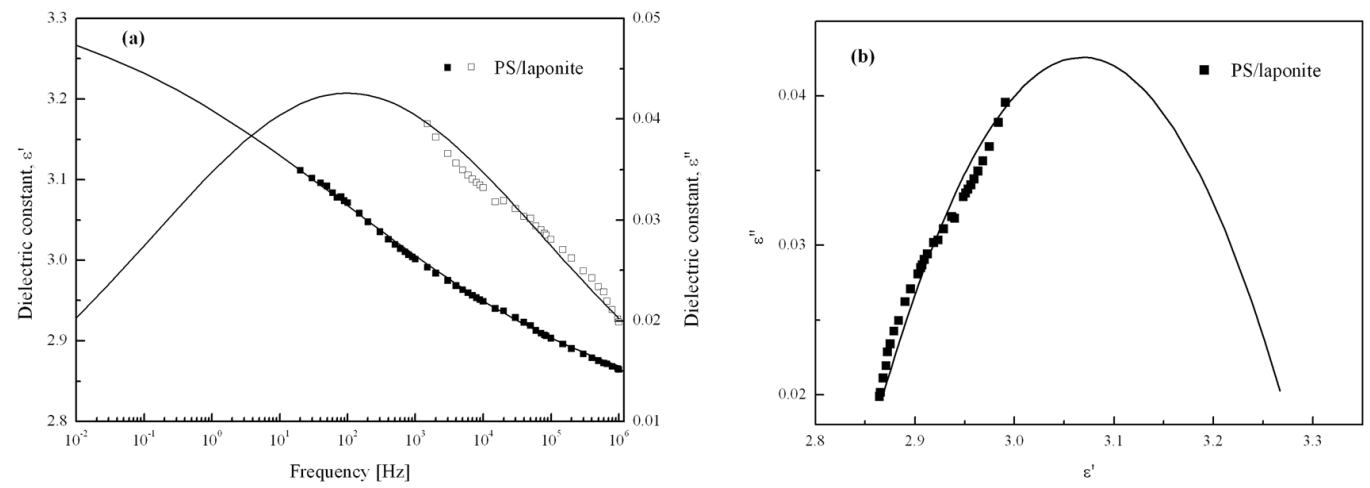

Figure 15. (a) Dielectric spectra ( $\varepsilon^{\prime}$ : closed symbols; $\varepsilon^{\prime \prime}$ : open symbols) and (b) Cole-Cole plot of the ER fluids. The fitting lines are generated from Equation (4) (Reprinted from Reference [53] with permission).

In Equation (4), $\varepsilon^{*}$ is a complex dielectric constant and $\varepsilon_{0}$ is the dielectric constant when $\omega$ approaches 0 . $\Delta \varepsilon$ is the difference between the dielectric constant at 0 and infinite frequency $\left(\varepsilon_{0}\right.$ and $\left.\varepsilon_{\infty}\right)$. They are the distribution curves over a broad frequency range. $\lambda$ is the dielectric relaxation time at the frequency of which the dielectric loss arrives the maximum value. The exponent $(1-\alpha)$ represents the broadness of the relaxation time distribution and $\alpha$ is a value in the range $0-1$. When $\alpha$ is zero, Equation (4) reduces to the Debye's single relaxation time model. $\Delta \varepsilon$ is the achievable polarizability in the ER fluids, which equals 0.546 . Owing to the laponite content in the PS/laponite particles, the value of $\Delta \varepsilon$ was much lower than those reported elsewhere [85-87]. A similar correlation between the dielectric properties and ER performance was also reported for the silica nanoparticle decorated polyaniline nanofiber-based ER fluid [88].

As shown in Figure 16, observing the relaxation behavior is one way of inspecting the phase change from a liquid-like to solid-like phase. The relaxation modulus $G(t)$ was calculated from the $G^{\prime}$ and $G^{\prime \prime}$ values using the typical formula known as the Schwarzl Equation, as given in Equation (5). Note that $G(t)$ is difficult to measure experimentally due to the intrinsic properties of the materials and the limitation of the mechanical measurements [89]. $G(t)$, as a function of time showed a linear increase with increasing electric field strength, which confirmed the strong interaction among PANI/HNT particles.

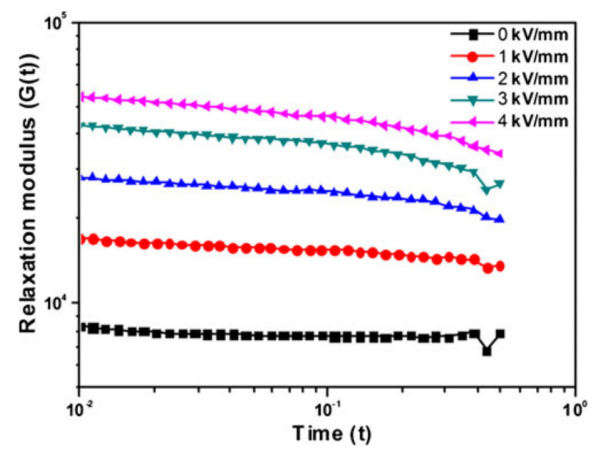

Figure 16. Relaxation modulus $G(t)$ of PANI/HNT composite-based ER fluid as calculated from $G^{\prime}(\omega)$ and $G^{\prime \prime}(\omega)$ (Reprinted from Reference [45] with permission). 


$$
G(t) \cong G^{\prime}(\omega)-0.560 G^{\prime \prime}\left(\frac{\omega}{2}\right)+0.200 G^{\prime \prime}(\omega)
$$

In addition, Table 1 summarizes fabrication method, clay content and slope of dynamic yield stress of most electro-responsive polymer/clay nanocomposites covered in this review. The slope of dynamic yield stress of the ER fluids ranged from 1.2 to 2, implying that the mechanism seems to be dependent on not only different materials but also different fabrication methods.

Table 1. Summary of electro-responsive polymer/clay nanocomposites with fabrication method, clay content and slope of dynamic yield stress.

\begin{tabular}{ccccc}
\hline $\begin{array}{c}\text { Polymer/Clay } \\
\text { Nanocomposites }\end{array}$ & Fabrication Method & $\begin{array}{c}\text { Clay Content } \\
\mathbf{( w t} \mathbf{\%})\end{array}$ & $\begin{array}{c}\text { Slope of Dynamic } \\
\text { Yield Stress }\end{array}$ & Reference \\
\hline PANI/MMT & In-situ polymerization & $0.75-3$ & - & {$[41]$} \\
PEA/MMT & In-situ polymerization & $0.5-5$ & - & {$[42]$} \\
PUA/MMT & Suspension polymerization & 5 & - & {$[47]$} \\
SAN/MMT & Emulsion polymerization & 4.76 & - & {$[49]$} \\
PANI/OMMT & Pickering emulsion polymerization & - & 1.5 & {$[52]$} \\
PIN/OMMT & In-situ polymerization & $5.5-12.1$ & - & {$[81]$} \\
PIN/kaolinite & cationic radical polymerization & $15-78$ & - & {$[80]$} \\
PANI/HNT & In-situ polymerization & - & 2 & {$[45]$} \\
PPy/HNT & In-situ polymerization & - & 1.5 & {$[68]$} \\
PANI/PAL & In-situ polymerization & - & 2 & {$[46]$} \\
PS/laponite & Pickering emulsion polymerization & 8.85 & 1.2 & {$[53]$} \\
\hline
\end{tabular}

\section{Conclusions}

Various electric stimuli-responsive polymer-clay nanocomposites synthesized by a range of methods were reviewed. SEM, TEM and XRD confirmed their successful intercalation. The thermal stability of the conducting polymer chain was also enhanced due to the shielding role of the clay. In addition, the conducting polymer/clay nanocomposite-based ER fluids also found showed excellent ER behaviors and follow the previously proposed CCJ model.

Acknowledgments: This work was supported by a research grant from National Research Foundation, Korea (NRF-2013R1A1A2057955).

Author Contributions: The whole process of preparation of this review has been initiated and guided by Hyoung Jin Choi, while Shang Hao Piao and Seung Hyuk Kwon wrote the original version of the manuscript.

Conflicts of Interest: The authors declare no conflict of interest.

\section{References}

1. Abranyi, A.; Szazdi, L.; Pukanszky, B.; Vancso, G.J.; Pukansky, B. Formation and detection of clay network structure in Poly(propylene)/layered silicate nanocomposites. Macromol. Rapid Commun. 2006, 27, 132-165. [CrossRef]

2. Messersmith, P.B.; Giannelis, E.P. Synthesis and characterization of layered silicate-expoxy nanocomposites. Chem. Mater. 1994, 6, 1719-1725. [CrossRef]

3. Ray, S.S.; Okamoto, M. Biodegradable polylactide and its nanocomposites: Opening a new dimension for plastics and composites. Macromol. Rapid Commun. 2003, 24, 815-840. [CrossRef]

4. Kuksenok, O.V.; Ruhwandl, R.W.; Shiyanovskii, S.V.; Terentjev, E.M. Director structure around a colloid particle suspended in a nematic liquid crystal. Phys. Rev. 1996, 54, 5198-5203. [CrossRef]

5. Chang, Y.M.; Tsai, Y.Y.; Huang, Y.P.; Chen, W.S.; Lee, W. Electrical and electro-optical properties of nematic-liquidcrystal-montmorillonite-clay nanocomposites. Jpn. J. Appl. Phys. 2007, 46, 7368-7370. [CrossRef]

6. Lim, S.T.; Hyun, Y.H.; Choi, H.J.; Jhon, M.S. Synthetic biodegradable aliphatic polyester/montmorillonite nanocomposites. Chem. Mater. 2002, 14, 1839-1844. [CrossRef] 
7. Alexandre, M.; Beyer, G.; Henrist, C.; Cloots, R.; Rulmant, A.; Jerome, R.; Dubois, P. Preparation and properties of layered silicate nanocomposites based on ethylene vinyl acetate copolymers. Macromol. Rapid Commun. 2001, 22, 643-646. [CrossRef]

8. Hyun, Y.H.; Lim, S.T.; Choi, H.J.; Jhon, M.S. Rheology of poly(ethylene oxide)/organoclay nanocomposites. Macromolecules 2001, 34, 8084-8093. [CrossRef]

9. Fong, H.; Vaia, R.A.; Sanders, J.H.; Lincoln, D.; Vreugdenhil, A.J.; Liu, W.D.; Bultman, J.; Chen, C.G. Self-passivation of polymer-layered silicate nanocomposites. Chem. Mater. 2001, 13, 4123-4129. [CrossRef]

10. Chen, B.Q.; Evans, J.R.G.; Greenwell, H.C.; Boulet, P.; Coveney, P.V.; Bowden, A.A.; Whiting, A. A critical appraisal of polymer-clay nanocomposites. Chem. Soc. Rev. 2008, 37, 568-594. [CrossRef] [PubMed]

11. Chen, G.M.; Liu, S.H.; Zhang, S.F.; Qi, Z.N. Self-assembly in a polystyrene/montmorillonite nanocomposite. Macromol. Rapid Commun. 2008, 21, 746-749. [CrossRef]

12. Wang, K.; Liang, S.; Du, R.N.; Zhang, Q.; Fu, Q. The interplay of thermodynamics and shear on the dispersion of polymer nanocomposite. Polymer 2004, 45, 7953-7960. [CrossRef]

13. Faguy, P.W.; Lucas, R.A.; Ma, W.L. An FT-IR-ATR spectroscopic study of the spontaneous polymerization of pyrrole in iron-exchanged montmorillonite. Colloid. Surf. Sci. A 1995, 105, 105-112. [CrossRef]

14. Carrado, K.A.; Xu, L.Q. In situ synthesis of polymer-clay nanocomposites from silicate gels. Chem. Mater. 1998, 10, 1440-1445. [CrossRef]

15. Ballav, N.; Sardar, P.S.; Ghosh, S.; Biswas, M. Polyaniline and polypyrrole modified conductive nanocomposites of polyfuran and polythiophene with montmorillonite clay. J. Ind. Eng. Chem. 2006, 41, 2959-2964. [CrossRef]

16. Masdarolomoor, F.; Innis, P.C.; Ashraf, S.; Kaner, R.B.; Walace, G.G. Nanocomposites of polyaniline/poly (2-methoxyaniline-5-sulfonic acid). Macromol. Rapid Commun. 2006, 27, 1995-2000. [CrossRef]

17. Yeh, J.M.; Chin, C.P.; Chang, S. Enhanced corrosion protection coatings prepared from soluble electronically conductive polypyrrole-clay nanocomposite materials. J. Appl. Polym. Sci. 2003, 88, 3264-3272. [CrossRef]

18. Choi, H.J.; Kim, S.G.; Hyun, Y.H.; Jhon, M.S. Preparation and rheological characteristics of solvent-cast poly(ethylene oxide)-montmorillonite nanocomposites. Macromol. Rapid Commun. 2001, 22, 320-325. [CrossRef]

19. Ogawa, M.; Ishii, T.; Miyamoto, N.; Kuroda, K. Intercalation of a cationic azobenzene into montmorillonite. Appl. Clay Sci. 2003, 22, 179-185. [CrossRef]

20. Ray, S.S.; Yamada, K.; Okamoto, M.; Ueda, K. Control of biodegradability of polylactide via nanocomposite technilogy. Macromol. Mater. Eng. 2003, 288, 203-208. [CrossRef]

21. Tjong, S.C.; Meng, Y.Z.; Hay, A.S. Novel preparation and properties of polypropylene-vermiculite nanocomposites. Chem. Mater. 2002, 14, 44-51. [CrossRef]

22. Manias, E.; Touny, A.; Wu, L.; Strawhecker, K.; Lu, B.; Chung, T.C. Polypropylene/montmorillonite nanocomposites. Review of the synthetic routes and materials properties. Chem. Mater. 2001, 13, 3516-3523. [CrossRef]

23. Caseri, W. Nanocomposites of polymers and metals or semiconductors: Historical background and optical properties. Macromol. Rapid Commun. 2000, 21, 705-722. [CrossRef]

24. Leroux, F.; Besse, J.P. Polymer interleaved layered double hydroxide: A new emerging class of nanocomosites. Chem. Mater. 2001, 13, 3507-3515. [CrossRef]

25. Fang, F.F.; Choi, H.J.; Joo, J. Conducting polymer/clay nanocomposites and their applications. J. Nanosci. Nanotechnol. 2008, 8, 1559-1581. [CrossRef] [PubMed]

26. Zhao, X.P.; Yin, J.B. Preparation and electrorheological characteristics of rare-earth-doped $\mathrm{TiO}_{2}$ suspensions. Chem. Mater. 2002, 14, 2258-2263. [CrossRef]

27. Loudet, J.C.; Poulin, P. Application of an electric field to colloidal particles suspended in a liquid-crystal solvent. Phys. Rev. Lett. 2001, 87, 165503. [CrossRef] [PubMed]

28. Oz, K.; Yavuz, M.; Yilmaz, H.; Unal, H.I.; Sari, B. Electrorheological properties and creep behavior of polyindole/poly(vinyl acetate) composite suspensions. J. Mater. Sci. 2008, 43, 1451-1459. [CrossRef]

29. Cheng, Y.C.; Guo, J.J.; Xu, G.J.; Cui, P.; Liu, X.H.; Liu, F.H.; Wu, J.H. Electrorheological property and microstructure of acetamide-modified $\mathrm{TiO}_{2}$ nanoparticles. Colloid Polym. Sci. 2008, 286, 1493-1497. [CrossRef]

30. Chin, B.D.; Lee, Y.S.; Park, O.O. Dielectric and rheological behaviors of semiconductive polymer suspension as an electrorheological fluid. J. Mod. Phys. B 1999, 13, 1852-1859. [CrossRef]

31. Kim, S.G.; Kim, J.W.; Jang, W.H.; Choi, H.J.; Jhon, M.S. Electrorheological characteristics of phosphate cellulose-based suspensions. Polymer 2001, 42, 5005-5012. [CrossRef]

32. Kim, J.W.; Liu, F.; Choi, H.J. Polypyrrole/clay nanocomposite and its electrorheological characteristics. J. Ind. Eng. Chem. 2002, 8, 399-403. 
33. Wen, W.J.; Huang, X.X.; Sheng, P. Electrorheological fluids, structures and mechanisms. Soft Matter 2008, 4, 200-210. [CrossRef]

34. Lei, X.P.; Liu, Y.S.; Su, Z.X. Synthesis and characterization of organo-attapulgite/polyaniline-dodecylbenzenesulfonic acid based on emulsion polymerization method. Polym. Compos. 2008, 29, 239-244. [CrossRef]

35. Chin, B.D.; Park, J.H.; Kwon, M.H.; Park, O.O. Rheological properties and dispersion stability of magnetorheological (MR) suspensions. Rheol. Acta 2001, 40, 211-219. [CrossRef]

36. Park, J.H.; Chin, B.D.; Park, O.O. Rheological properties and stabilization of magnetorheological fluids in a water-in-oil emulsion. J. Colloid Interf. Sci. 2001, 240, 349-354. [CrossRef] [PubMed]

37. Lim, S.T.; Cho, M.S.; Jang, I.B.; Choi, H.J. Magnetorheological characterization of carbonyl iron based suspension stabilized by fumed silica. J. Magn. Magn. Mater. 2004, 282, 170-173. [CrossRef]

38. Bossis, G.; Abbo, C.; Cutillas, S.; Lacis, S.; Métayer, C. Electroactive and electrostructured elastomers. Int. J. Mod. Phys. B 2001, 15, 564-573. [CrossRef]

39. Kim, J.W.; Kim, C.A.; Choi, H.J.; Choi, S.B. Role of surfactant on damping performance of polyaniline based electrorheological suspension. Korea Aust. Rheol. J. 2006, 18, 25-30.

40. Ruiz-Hitzky, E.; Aranda, P.; Casal, B.; Galván, J.C. Nanocomposite materials with controlled ion mobility. Adv. Mater. 1995, 7, 180-184. [CrossRef]

41. Yeh, J.M.; Liou, S.J.; Lai, C.Y.; Wu, P.C. Enhancement of corrosion protection effect in polyaniline via the formation of polyaniline-clay nanocomposite materials. Chem. Mater. 2001, 13, 1131-1136. [CrossRef]

42. Yeh, J.M.; Chen, C.L.; Chen, Y.C.; Ma, C.Y.; Lee, K.R.; Wei, Y.; Li, S.X. Enhancement of corrosion protection effect of poly(o-ethoxyaniline) via the formation of poly (o-ethoxyaniline)-clay nanocomposite materials. Polymer 2002, 43, 2729-2736. [CrossRef]

43. Zhou, C.; Du, X.; Liu, Z.; Mai, Y.W.; Ringer, S.P. Multi-holed clay nanotubes and their modification with a polyaniline nanolayer. J. Mater. Sci. 2011, 46, 446-450. [CrossRef]

44. Zhang, L.; Wang, T.; Liu, P. Polyaniline-coated halloysite nanotubes via in-situ chemical polymerization. Appl. Surf. Sci. 2008, 255, 2091-2097. [CrossRef]

45. Zhang, W.L.; Choi, H.J. Fabrication of semiconducting polyaniline-wrapped halloysite nanotube composite and its electrorheology. Colloid Polym. Sci. 2012, 290, 1743-1748. [CrossRef]

46. Chae, H.S.; Zhang, W.L.; Piao, S.H.; Choi, H.J. Synthesized palygorskite/polyaniline nanocomposite particles by oxidative polymerization and their electrorheology. Appl. Clay Sci. 2015, 107, 165-172. [CrossRef]

47. Jun, J.B.; Suh, K.D. Preparation and electrorheological characterization of suspensions of poly(urethane acrylate)/clay nanocomposite particles. J. Appl. Polym. Sci. 2003, 90, 458-464. [CrossRef]

48. Tong, X.; Zhao, H.; Tang, T.; Feng, Z.; Huang, B. Preparation and characterization of poly(ethyl acrylate)/bentonite nanocomposites by in situ emulsion polymerization. J. Polym. Sci. A Polym. Chem. 2002, 40, 1706-1711. [CrossRef]

49. Kim, J.W.; Jang, L.W.; Choi, H.J.; Jhon, M.S. Physical and electroresponsive characteristics of the intercalated styrene-acrylonitrile copolymer/clay nanocomposite under applied electric fields. J. Appl. Polym. Sci. 2003, 89, 821-827. [CrossRef]

50. Tang, J.; Quinlan, P.J.; Tam, K.C. Stimuli-responsive Pickering emulsions: Recent advances and potential applications. Soft Matter 2015, 11, 3512-3529. [CrossRef] [PubMed]

51. Piao, S.H.; Kwon, S.H.; Zhang, W.L.; Choi, H.J. Celebrating soft matter's 10th anniversary: Stimuli-responsive Pickering emulsion polymerized smart fluids. Soft Matter 2015, 11, 646-654. [CrossRef] [PubMed]

52. Fang, F.F.; Liu, Y.D.; Choi, H.J. Synthesis and electrorheological characteristics of polyaniline/organoclay nanoparticles via Pickering emulsion polymerization. Smart Mater. Struct. 2010, 19, 124002. [CrossRef]

53. Kim, Y.J.; Liu, Y.D.; Choi, H.J.; Park, S.J. Facile fabrication of Pickering emulsion polymerized polystyrene/laponite composite nanoparticles and their electrorheology. J. Colloid Interf. Sci. 2013, 394, 108-114. [CrossRef] [PubMed]

54. Park, J.U.; Choi, Y.S.; Cho, K.S.; Kim, D.H.; Ahn, K.H.; Lee, S.J. Time-electric field superposition in electrically activated polypropylene/layered silicate nanocomposites. Polymer 2006, 47, 5145-5153. [CrossRef]

55. Kim, D.H.; Park, J.U.; Cho, K.S.; Ahn, K.H.; Lee, S.J. A novel fabrication method for poly(propylene)/clay nanocomposites by continuous processing. Macromol. Mater. Eng. 2006, 291, 1127-1135. [CrossRef]

56. Strounina, E.V.; Shepherd, R.; Kane-Maguire, L.A.P.; Wallace, G.G. Conformational changes in sulfonated polyaniline caused by metal salts and $\mathrm{OH}^{-}$. Synth. Met. 2003, 135/136, 289-290. [CrossRef]

57. Bon, S.A.F.; Chen, T. Pickering stabilization as a tool in the fabrication of complex nanopatterned silica microcapsules. Langmuir 2007, 23, 9527-9530. [CrossRef] [PubMed] 
58. Bon, S.A.F.; Chen, T. Pickering miniemulsion polymerization using laponite clay as a stabilizer. Langmuir 2007, 23, 8316-8322. [CrossRef] [PubMed]

59. Negrete-Herrera, N.; Putaux, J.L.; David, L.; Bourgeat-Lami, E. Polymer/laponite composite colloids through emulsion polymerization: Influence of the clay modification level on particle morphology. Macromolecules 2006, 39, 9177-9184. [CrossRef]

60. Fang, F.F.; Kim, J.H.; Choi, H.J.; Kim, C.A. Synthesis and electrorheological response of nano-sized laponite stabilized poly(methyl methacrylate) spheres. Colloid Polym. Sci. 2009, 287, 745-749. [CrossRef]

61. Fang, F.F.; Choi, H.J.; Seo, Y.S. Novel fabrication of polyaniline particles wrapped by exfoliated clay sheets and their electrorheology. J. Nanosci. Nanotechnol. 2009, 9, 1-5. [CrossRef]

62. Vaia, R.A.; Giannelis, E.P. Polymer melt intercalation in organically-modified layered silicates: Model predictions and experiment. Macromolecules 1997, 30, 8000-8009. [CrossRef]

63. Lee, D.K.; Lee, S.H.; Char, K.; Kim, J. Expansion distribution of basal spacing of the silicate layers in polyaniline/Na-montmorillonite nanocomposites monitored with X-ray diffraction. Macromol. Rapid Commun. 2000, 21, 1136-1139. [CrossRef]

64. Jin, E.; Lu, X.F.; Bian, X.J.; Kong, L.R.; Zhang, W.J.; Wang, C. Unique tetragonal starlike polyanilinemicrostructure and its application in electrochemical biosensing. J. Mater. Chem. 2010, 20, 3079-3083. [CrossRef]

65. Wang, J.H.; Han, X.J.; Ma, H.R.; Ji, Y.F.; Bi, L.J. Adsorptive removal of humic acid from aqueous solution on polyaniline/attapulgite composite. Chem. Eng. J. 2011, 173, 171-177. [CrossRef]

66. Agag, T.; Koga, T.; Takeichi, T. Thermal and mechanical properties of polyimide-clay nanocomposites. Polymer 2001, 42, 3399-3408. [CrossRef]

67. Jang, B.Z. Control of interfacial adhesion in continuous carbon and Kevlar fiber reinforced polymer composites. Compos. Sci. Technol. 1992, 44, 333-349. [CrossRef]

68. Jang, D.S.; Zhang, W.L.; Choi, H.J. Polypyrrole-wrapped halloysite nanocomposite and its rheological response under electric fields. J. Mater. Sci. 2014, 49, 7309-7316. [CrossRef]

69. Jang, J.S.; Yoon, H.S. Novel fabrication of size-tunable silica nanotubes using a reverse-microemulsion-mediated sol-gel method. Adv. Mater. 2004, 16, 799-802. [CrossRef]

70. Nicolini, K.P.; Fukamachi, C.R.B.; Wypych, F.; Mangrich, A.S. Dehydrated halloysite intercalated mechanochemically with urea: Thermal behavior and structural aspects. J. Colloid Interface Sci. 2009, 338, 474-479. [CrossRef] [PubMed]

71. Park, D.P.; Lim, S.T.; Lim, J.Y.; Choi, H.J.; Choi, S.B. Electrorheological characteristics of solvent-cast polypyrrole/clay nanocomposite. J. Appl. Polym. Sci. 2009, 112, 1365-1371. [CrossRef]

72. Parthasarathy, M.; Klingenberg, D.J. Electrorheology: Mechanisms and models. Mater. Sci. Eng. 1996, 17, 57-103. [CrossRef]

73. Davis, L.C. Polarization forces and conductivity effects in electrorheological fluids. J. Appl. Phys. 1992, 72, 1334-1340. [CrossRef]

74. Hao, T.; Kawai, A.; Ikazaki, F. Mechanism of the electrorheological effect-Evidence from the conductive, dielectric, and surface characteristics of water-free electrorheological fluids. Langmuir 1998, 14, 1256-1262. [CrossRef]

75. Cho, M.S.; Cho, Y.H.; Choi, H.J.; Jhon, M.S. Synthesis and electrorheological characteristics of polyaniline-coated poly(methyl methacrylate) microsphere: Size effect. Langmuir 2003, 19, 5875-5881. [CrossRef]

76. Cho, M.S.; Choi, H.J.; Jhon, M.S. Shear stress analysis of a semiconducting polymer based electrorheological fluid system. Polymer 2005, 46, 11484-11488. [CrossRef]

77. Choi, H.J.; Park, S.H.; Yoon, J.S.; Lee, H.S.; Choi, S.J. Rheological study on poly-D(-)(3-hydroxybutyrate) and its blends with poly(ethylene oxide). Polym. Eng. Sci. 1995, 35, 1636-1642. [CrossRef]

78. Fang, F.F.; Liu, Y.D.; Lee, I.S.; Choi, H.J. Well controlled core/shell type polymeric microspheres coated with conducting polyaniline: Fabrication and electrorheology. RSC Adv. 2011, 1, 1026-1032. [CrossRef]

79. Erol, O.; Karakisla, M.; Unal, H.I.; Sacak, M. Electrorheological properties of polyaniline/K-feldspar conducting composite. J. Compos. Mater. 2012, 46, 1295-1304. [CrossRef]

80. Eristi, C.; Yavus, M.; Yilmaz, H.; Sari, B.; Unal, H.I. Synthesis, characterization and electrorheological properties of polyindene/kaolinite composites. J. Macromol. Sci. A Pure Appl. Chem. 2007, 44, 759-767. [CrossRef]

81. Guzel, S.; Erol, O.; Unal, H.I. Polyindene/Organo-montmorillonite conducting nanocomposites. II. Electrorheological properties. J. Appl. Polym. Sci. 2012, 124, 4935-4944. [CrossRef] 
82. Lu, J.; Zhao, X.P. Electrorheological properties of suspensions based on polyaniline-montmorillonite clay nanocomposite. J. Mater. Res. 2002, 17, 1513-1519. [CrossRef]

83. Erol, O.; Unal, H.I.; Sari, B. Synthesis, electrorheology, and creep behaviors of in situ intercalated polyindole/organo-montmorillonite conducting nanocomposite. Polym. Compos. 2010, 31, 471-481.

84. Yin, J.B.; Xia, X.; Zhao, X.P. The electrorheological effect and dielectric properties of suspensions containing polyaniline@tutania nanocable-like particles. Soft Matter 2011, 7, 10978-10986. [CrossRef]

85. Liu, C.; Li, C.; Chen, P.; He, J.; Fan, Q. Influence of long-chain branching on linear viscoelastic flow properties and dielectric relaxation of polycarbonates. Polymer 2004, 45, 2803-2812. [CrossRef]

86. Pluta, M.; Jeszka, J.K.; Boiteux, G. Polylactide/montmorillonite nanocomposites: Structure, dielectric, viscoelastic and thermal properties. Eur. Polym. J. 2007, 43, 2819-2835. [CrossRef]

87. $\mathrm{Xu}, \mathrm{J}$.; Wong, C.P. Characterization and properties of an organic-inorganic dielectric nanocomposite for embedded decoupling capacitor applications. Compos. A 2007, 38, 13-19. [CrossRef]

88. Liu, Y.D.; Fang, F.F.; Choi, H.J. Silica nanoparticle decorated polyaniline nanofiber and its electrorheological response. Soft Matter 2011, 7, 2782-2789. [CrossRef]

89. Schwarzl, F.L. Numerical calculation of stress relaxation modulus from dynamic data for linear viscoelastic materials. Rheol. Acta 1975, 14, 581-590. [CrossRef]

(C) 2016 by the authors; licensee MDPI, Basel, Switzerland. This article is an open access article distributed under the terms and conditions of the Creative Commons by Attribution (CC-BY) license (http://creativecommons.org/licenses/by/4.0/). 